\title{
A SBPC E A INFORMAÇÃO AMBIENTAL NO BRASIL: O PAPEL DA REVISTA CIÊNCIA HOJE'
}

\author{
Antonio Teixeira de BARROS ${ }^{2}$
}

\section{RESUMO}

Analisa a informação ambiental divulgada pela revista Ciência Hoje, editada pela Sociedade Brasileira para o Progresso da Ciência (SBPC), desde o primeiro número da revista até a realização da Eco 92. A divulgação concentra-se nos estudos de avaliação de impactos e efeitos da degradação ambiental e nos temas globais da agenda ecológica. O didatismo é uma das características principais de Ciência Hoje, com o intuito de facilitar a leitura por parte do público leigo.

Palavras-chave: informação ambiental; ecologia; revista Ciência Hoje; Sociedade Brasileira para o Progresso da Ciência; comunicação científica; informação científica.

\section{ABSTRACT}

This article analyzes the environmental information disclosed by the journal "Ciência Hoje", published by the "Sociedade Brasileira para o Progresso da Ciência" (SBPC), from the first number of the journal to the accomplishment of the "Eco 92". It concentrates on studies of evaluation of impacts, effects of environmental degradation and global themes of the ecological calendar. The didactic aspect is one of the main characteristics of "Ciência Hoje", with the aim of facilitating the reading to the public.

Keywords: environmental information; ecology; journal magazine "Ciência Hoje"; "Sociedade Brasileira para o Progresso da Ciência"; scientific communication; scientific information.

\section{INTRODUÇĀO}

O objetivo geral deste trabalho é analisar como se deu a atuação da Sociedade Brasileira para o Progresso da Ciência (SBPC) em termos de divulgação científica, quanto à questão ambiental no Brasil, com base na trajetória da revista Ciência Hoje, criada em 1982, até 1992, quando aconteceu a Eco 92. Especificamente, pretendemos examinar o enfoque adotado, ou seja, o tipo de abordagem e as temáticas enfatizadas.

\footnotetext{
(1) Elaborado com base na Tese de Doutoramento do autor, intitulada "Atores e Discursos Ecológicos no Brasil: Ciência, Estado e Imprensa (197292)", apresentada ao Departamento de Sociologia da Universidade de Brasília, sob a orientada da Profa. Dra. Fernanda Sobral, em 1999.

(2) Doutor em Sociologia, Professor do Instituto de Ciências Sociais Aplicadas do Centro Universitário de Brasília - UniCEUB.
} 
Partimos da hipótese geral de que a divulgação científica sobre meio ambiente, protagonizada pela comunidade científica, em muito contribuiu para que a ecologia se tornasse, nos últimos anos, tema de amplo interesse social, deixando de ser objeto de estudo apenas de áreas específicas. As sociedades científicas começaram a debater o assunto em congressos e conferências, alertando para a dimensão política e social do problema; a imprensa passou a conferir importância a tais manifestações; os governos começaram a sentir-se pressionados por organismos internacionais para agirem de forma a coibir atos abusivos contra a natureza.

Outra hipótese é a de que os estudos científicos, mesmo aqueles dirigidos ao público de não produtores de conhecimento científico, comoé o caso dos artigos publicados por Ciência Hoje, contribuem para que esse público interprete adequadamente os fatos ecológicos. Isso porque os cientistas estendem os questionamentos do campo ecológico a um contexto mais amplo, abrangendo todo o sistema mundial de produção. Esse discurso propõe-se ainda a criticar o modo de vida e o modo de produção na sociedade industrial, como é o caso das Ciências Sociais. No caso específico do Brasil, foi desse ramo das ciências que surgiram relevantes contribuições relativas às conseqüências da exploração indiscriminada de recursos naturais e acerca dos riscos da poluição urbana (Maculan, 1995).

No âmbito de um processo de revisão teórica e metodológica do campo das Ciências Sociais, a partir da década de 1980, amplia-se o interesse acerca dos fundamentos epistemológicos de uma nova área: as ciências sociais do ambiente, entendidas como um novo domínio inter e transdisciplinar. As primeiras iniciativas situam-se no campo de investigação denominado ecológico-político, ou seja, uma tentativa de compreender o contexto que propiciou a formação do ambientalismo no Brasil e na América Latina, bem como a instituição de suas estratégias, procedimentos e protocolos formais. A confluência da Sociologia e da Ciência Política foi de grande importância nesse processo, gerando grandes contribuições teóricas. Partia-se do pressuposto de que para se compreender a crise ecológica global seria necessário, antes, refletir à luz dos princípios que regem a organização e o funcionamento do sistema sócio-político contemporâneo. A crise ambiental, nesta perspectiva, era concebida como uma crise da forma de ocupação humana do planeta terra, devendo ser interpretada, portanto, como parte de um horizonte mais amplo, ou seja, a crise dos fundamentos da vida política e social (Leis,1996).

Diante do exposto, cabe destacar o pioneirismo da Sociedade Brasileira para o Progresso da Ciência (SBPC), tanto no plano científico como no político. Enquanto a temática só passou a preocupar outras instituições científicas brasileiras após a Conferência de Estocolmo, a SBPC, muito antes, desde 1965, já se ocupava com a questão, como registram Fernandes (1990) e Ferreira (1993), ano em que publicou um "Apelo aos governos, reitores e diretores de institutos cientificos": Uma moção, em número posterior, pedia a criação de um organismo federal responsável por todos os aspectos de preservação da natureza e proteção dos recursos naturais do Brasil. Outra contribuição importante da SBPC diz respeito ao envolvimento da comunidade científica brasileira com a questão ecológica e ambiental, a partir da metade da década de 1980, principalmente no que concerne à necessidade de uma abordagem interdisciplinar.

A SBPC contribuiu também para intensificar o debate acadêmico sobre a questão, por intermédio dos seminários nacionais "Universidade e Meio Ambiente", promovidos a partir de 1986, sempre uma vez a cada ano. Tal iniciativa representou um passo importante para criar um fórum de debate continuado no âmbito da comunidade científica brasileira sobre os temas atinentes à educação ambiental, à pesquisa científica e demais temas de interesse acadêmico no âmbito da temática ecológico-ambiental.

A situação alarmante da cidade industrial de Cubatão, no estado de São Paulo, fez com que a SBPC instituísse o ciclo de simpósios "Estocolmo 72 X Cubatão 82", durante a 34a. Reunião Anual. Esta iniciativa oportunizou a discussão sobre "os resultados de dez anos da política ambiental desastrosa inaugurada pelo Brasil na Suécia" (Ferreira,1993, p.129). Como ressalta a mesma autora, a SBPC exerceu relevante papel no processo de politização do descontentamento popular acerca da situação cubatense. 
Outra contribuição essencial da SBPC está na criação do Grupo Interdisciplinar de Estudos sobre Cubatão, o que contribuiu sobremaneira para que se debatesse não apenas o caso específico de Cubatão, mas da região Sudeste e do Brasil, de modo geral. É oportuno mencionar ainda a contribuição da entidade para a inclusão de um capítulo sobre ecologia na Constituição Federal de 1988. A Comissão Especial de Estudos sobre Meio Ambiente elaborou um texto e apresentou à Assembléia Nacional Constituinte, a qual acatou a proposta quase integralmente.

\section{DESCRIÇÃO DA PESQUISA E DA METODOLOGIA}

Para a consecução dos objetivos propostos, optamos pela análise de conteúdo (AC), entendida como "um conjunto de técnicas de análise das comunicações" (Bardin, 1977, p.31). Por essa razão, alega o mesmo autor, deve-se entender a $\mathrm{AC}$ não como um instrumento, mas "um leque de apetrechos; ou, com maior rigor, será um único instrumento, mas marcado por uma grande disparidade de formas e adaptável a um campo de aplicação muito vasto: as comunicações" (p.31). Aqui, adotamos um dos procedimentos específicos desse "conjunto de apetrechos", a análise categorial, a qual, conforme a autora citada,

"pretende tomar em consideração a totalidade de um texto, passando-o pelo crivo da classificação e do recenseamento, segundo a freqüência de presença (ou de ausência) de itens de sentido. Isso pode constituir um primeiro passo, obedecendo ao princípio de objetividade e racionalizando através de números e percentagem, uma interpretação que, sem ela, teria de ser sujeita a aval.

É o método das categorias, espécie de gavetas ou rubricas significativas que permitem a classificação dos elementos de significação constitutiva, da mensagem. É, portanto, um método taxionômico bem concebtdo para (...) introduzir uma ordem, segundo certos critérios, na desordem aparente" (Bardin,1977, p.37)

Para a análise utilizamos o conjunto total dos textos publicados por Ciência Hoje, periódico de divulgação científica publicado pela SBPC , o qual cobre diversas áreas científicas.

Após a catalogação de todos os textos sobre ecologia e meio ambiente, publicados pelo periódico, totalizando 166 textos - entre notas, artigos científicos e comentários -, estabelecemos as seguintes categorias tematicas:

1- Agricultura e Meio Ambiente - enfoques que relacionam as práticas agrícolas com a ecologia;

2 - Amazônia - estudos que abordam especificamente a região amazônica;

3 - Devastação Desmatamento- exame dos efeitos e conseqüências, fora do contexto amazônico;

4 -Eco-História - pesquisas que traçam uma história dos desastres ambientais no Brasil;

5 -Ecossistemas Aquáticos - matérias referentes a mares, rios, lagos, lagoas e brejos, e os seres que neles habitam;

6 - Espécies em Extinção - artigos que abordam a situação das espécies animais e vegetais ameaçadas de extinção;

7 - Fauna/Flora - pesquisas sobre a vida animal e/ou vegetal e sua importância no equilíbrio ecológico;

8 - Informação Ambiental - aspectos atinentes ao universo da informação e documentação no campo da ecologia;

9 -Parques Nacionais/estações/reservas ecológicas - textos que enfocam assuntos relacionados com o mapeamento ecológico, diagnóstico ambiental e situação geral dos parques, reservas e estações ecológicas no Brasil;

10 - Política Ambiental - informações relativas à elaboração e implementação de políticas públicas "verdes";

11 - Poluição - temas centrados nas diversas formas de poluição ambiental, sobretudo a industrial;

12 - Rio 92 - opiniões, dados e informações sobre os preparativos para a Rio 92;

\section{CIÊNCIA HOJE E A DIVULGAÇÃO CIENTÍFICA SOBRE ECOLOGIA NO BRASIL}

Há acentuado e crescente interesse da revista Ciência Hoje pela temática ambiental. 
Além disso, notamos que Ciência Hoje concentrou-se em temas de maior interesse do público geral, o que demonstra o quanto a problemática ecológica deixou de ser de interesse apenas de especialistas, uma vez que o periódico em questão tem como objetivo a difusão científica para um público mais amplo. Ciência Hoje atribuiu grande importância à Amazônia e aos problemas da poluição industrial.

\section{AMAZÔNIA}

No que diz respeito à categoria Amazônia, a mais importante na cobertura de Ciência Hoje, com $39,80 \%$ do total de textos, podemos observar na Tabela 1 como se deu a distribuição dos textos ao longo do período estudado, por ordem de importância. Merece destaque o fato de o ano de 1991 apresentar o maior índice de textos, o que se justifica pela publicação de um número especial sobre a Amazônia. A referida edição confirma a importância que tem esta categoria no âmbito do discurso científico sobre meio ambiente. Destaca-se a agressão aos recursos florestais, cuja análise será apresentada a seguir considerando-se os aspectos gerais e específicos.
Recursos florestais amazônicos - plano geral

A questão relativa à floresta amazônica foi o carro-chefe da cobertura de Ciência Hoje no período.

Dos 66 textos atinentes aos ecossistemas amazônicos, 35 abordam aspectos florestais, dos quais 14 tratam de problemas gerais da região como um complexo ambiental e 21 se detêm ao exame de questões localizadas, de zonas fitogeográficas determinadas. No primeiro caso, temos como eixo a preocupação dos cientistas com o equilíbrio da biodiversidade. A ameaça a este equilíbrio, conforme os artigos examinados, provém principalmente da exploração da madeira. Dos 15 artigos que analisam esta questão (do total de 35), 12 enfatizam este argumento.

Outro texto ressalta que "... a ação corrosiva de moto-serras nos troncos de suas árvores" e os "incêndios criminosos engolem anualmente fatias expressivas de suas florestas"; fazendo com que o seu futuro "seja tão preocupante quanto a ameaça de um desastre nuclear" ("Um Desafio para o Futuro" - Especial Amazônia, 1991). Dez outros textos concentram-se no exame da ameaça à diversidade vegetal,

Tabela 1. Ciência Hoje - Classificação Temática

\begin{tabular}{lccccccccccccc}
\hline CATEGORIAS/ANO & 82 & 83 & 84 & 85 & 86 & 87 & 88 & 89 & 90 & 91 & 92 & Total & $\%$ \\
\hline Amazônia & 01 & - & 01 & 03 & 01 & 02 & 04 & 07 & 10 & 27 & 10 & 66 & 39,8 \\
Poluição & 07 & 01 & 02 & 01 & - & 03 & 02 & 02 & 02 & 02 & 03 & 27 & 16,0 \\
Agricultura e Meio Ambiente & 01 & 02 & - & - & 05 & - & 01 & 04 & - & - & 02 & 15 & 9,0 \\
Fauna / Flora & - & 02 & - & 01 & - & 01 & - & 01 & 02 & 03 & 04 & 14 & 8,4 \\
Ecossistemas Aquáticos & - & - & - & - & 02 & 01 & - & 01 & 01 & - & 04 & 09 & 5,4 \\
Espécies em Extinção & 01 & 01 & 02 & 01 & - & 02 & - & 02 & - & - & - & 09 & 5,4 \\
Eco-História & - & - & - & 01 & - & - & 01 & 02 & - & 02 & - & 06 & 3,6 \\
Devastação/Desmatamento & - & - & - & 01 & 01 & 01 & 03 & - & - & - & - & 06 & 3,6 \\
Parques/Reservas/Estações Ecológicas & 01 & 02 & - & - & - & - & 02 & - & - & - & - & 05 & 3,0 \\
Política Ambiental & - & - & - & - & - & 01 & - & - & - & - & 03 & 04 & 2,4 \\
Rio92 & - & - & - & - & - & - & - & - & - & - & 04 & 04 & 2,4 \\
TOTAL & 05 & 09 & 06 & 08 & 08 & 11 & 13 & 19 & 15 & 34 & 30 & 156 & 100 \\
\hline
\end{tabular}


devido aos projetos de desenvolvimento baseados na abertura de estradas, no extrativismo madeireiro e na construção de hidrelétricas e barragens. Além de ressaltar conseqüências específicas do desflorestamento no complexo amazônico, alguns comentários de cientistas advertem para as questões relativas ao ecossistema em sua totalidade, uma vez que a destruição progressiva de áreas florestais implica, inexoravelmente, na dizimação de espécies animais, cuja conseqüência direta é o desequilíbrio ecológico da região, pois,

"... estima-se que a remoção da luxuriante cobertura vegetal alcance aproximadamente quinhentas toneladas por hectare. O desmatamento afeta o delicado equilíbrio da floresta. Entre as muitas alterações gue provoca, uma das mais sérias é a redução da diversidade biológica, com a extinção de espécies. A exploração de riquezas da região vem sendo feita sem a preocupação de preservar as matas, a fauna, os rios..." ("Maneje com cuidado: frágil", set.1989).

Outro dado relevante é o confronto do discurso científico com o discurso governamental. Alguns pesquisadores questionam, por exemplo, a validade dos dados ambientais divulgados por fontes oficiais sobre o desmatamento na Amazônia Legal, a partir de imagens captadas pelo satélite Landsat. "As informações que essas imagens fornecem, entretanto, são desatualizadas e pouco confiáveis para desmatamentos mais antigos; além disso, são geralmente apresentadas de um modo que dá ênfase ao aspecto mais tranquiilizador - mas menos importante - dos resultados" (grifo nosso). Como exemplo, o mesmo estudo menciona o fato de que, em 1980, o Instituto de Pesquisas Espaciais (INPE) divulgou um estudo de interpretação das imagens da Amazônia tomadas em 1975 e 1978. A partir desse estudo, generalizouse a impressão de que apenas 1,55 da Amazônia Legal tinham sido desmatados, "subestimando-se substancialmente o desmatamento que vinha então ocorrendo - o que se pode facilmente deduzir de uma comparação entre os valores constatados no estudo e o que se verifica por observação direta, em terra..." ("A floresta vai acabar?" - jan./fev.1984).
Outros artigos ressaltam dados estatísticos, como os que constatam que as florestas tropicais úmidas da terra vêm sendo destruídas na velocidade de 20 hectares por minuto, por meio do extrativismo seletivo de madeiras e outras formas de desmatamento. A preocupação com a extração de madeiras é justificada pelo fato de que, apesar do avanço continuado da devastação, a floresta amazônica, nos seus 260 milhões de hectares, ainda "guarda mais de 2.300 espécies vegetais, distribuídas em cerca de 700 gêneros e 120 famílias", sendo a grande maioria dessas espécies produtoras de madeira ("Anatomia da Madeira", Especial Amazônia,1991). Um aspecto enfatizado é o lento processo natural de construção do equilíbrio biológico, até atingir a maturidade ecossistêmica. O cerne da preocupação dos cientistas quanto a isso é que esse equilíbrio, sabiamente construído ao longo de tanto tempo, sofre cada vez mais ameaças, tanto pela exploração continuada de madeira, como pela inundação de áreas florestais, resultado da construção de barragens e hidrelétricas, causan-do a expulsão de milhares de animais de seu habitat.

Apesar da devastação continuada e da ameaça de extinção, um botânico salienta a dificuldade de identificação das espécies vegetais, devido à "vastidão das terras e à heterogeneidade das espécies", além da grande quantidade. O fato de serem identificadas corretamente e sua exploração ocorrer com base na utilização de uma nomenclatura vulgar, facilita a inclusão de espécies diferentes na mesma denominação.

Com isso, além do risco de comprometer a biodiversidade da região, há ainda o risco econômico, pois algumas espécies nobres podem ser vendidas a preços subestimados.

\section{Recursos florestais amazônicos - enfoques específicos}

A devastação no estado do Pará é o aspecto mais abordado pela revista Ciência Hoje, no âmbito da categoria Amazônia, no que se refere aos recursos florestais, quando se trata de enfoques específicos. Em seguida estão o desflorestamento em Rondônia, Acre e Maranhão. 


\section{A devastação no estado do Pará}

O estado do Pará foi o que mais despertou o interesse dos cientistas quanto à questão ambiental na revista Ciência Hoje. Dos 21 estudos sobre zonas fitogeográficas determinadas, dez referemse ao Pará, seis dos quais ao município de Paragominas. A primeira indagação que surge, após tal constatação é: por que esse Estado (e mais especificamente esse município) tornou-se objeto de estudo tão importante para a comunidade científica? O que há de especial nessa área?

Situado ao longo da rodovia Belém-Brasília, construída em 1960, no leste do estado, o município de Paragominas, com $22 \mathrm{mil} \mathrm{km}^{2}$, registrou um acelerado povoamento após a construção da rodovia, contando com incentivos governamentais, além do baixo preço da terra, o que causou grande interesse de pecuaristas e especuladores dos estados de Minas Gerais e Goiás. Para obter o título de posse da terra, o Instituto de Colonização e Reforma Agrária (INCRA) exigia que os ocupantes desmatassem um sexto da área pleiteada. A partir de 1970, esse modelo de exploração entrou em crise. Além disso, os bancos reduziram o apoio financeiro aos pecuaristas. Com isso, implantou-se uma nova forma de exploração econômica: a indústria madeireira. Desde então, tal atividade tem causado danos permanentes às formações florestais da região. Em 1987, apenas na cidade, havia 400 serrarias. Hoje, este município é o maior centro madeireiro do País. Dados mencionados nos artigos revelam que a exploração madeireira reduziu a cobertura da floresta de $82 \%$ para $45 \%$, em pouco mais de duas décadas. Tudo porque

"pratica-se ali intensamente a extração seletiva, atividade muito rentável, mas irracional e sem futuro. Em cinco anos, pouco restará das madeiras nobres da região. A remoção sistemática das árvores que ostentam determinadas características tende a causar gradativo empobrecimento no patrimônio genético das espécies madeireiras. Mas não é só: todas as florestas do Parápoderão esgotarse em duas ou três gerações... " ("Seleção predatória", jul.1989).
Existem, ainda, na região outras atividades predatórias típicas como a agricultura de corte, queimada e mineração. É por isso que Paragominas é caracterizado como "um microcosmo da Amazônia". Em um dos textos, lemos que "as lições extraídas do modelo Paragominas pode, portanto, influir nos rumos do desenvolvimento da Amazônia". É necessário esclarecer ainda que o ponto de vista que os pesquisadores defendem não é o da intocabilidade conservacionista, mas tão-somente um novo modelo econômico: a exploração sustentada.

Vale ressaltarmos ainda que os artigos que enfocam as conseqüências da mineração no estado do Pará enfatizam a "complexidade da questão", na qual estão envolvidos ao mesmo tempo "problemas de fluxo financeiro, dívida externa, mineração, ecologia, agropecuária, exploração florestal, antropologia, identidade cultural, energia, transportes e pesquisa científica" ("Carajás: o grande desafio", nov./dez.1982).

Mais uma vez constata-se o confronto com o discurso oficial. Um dos textos afirma que o Governo, quase sempre, é cúmplice da exploração econômica predatória na região, visto que "os incentivos oficiais destinam-se mais a promover as atividades extrativas do que a estimular a implantação de formas racionais de manejo" ("Seleção predatória", jul.1989).

\section{Perdendo Rondônia}

$\mathrm{O}$ estado de Rondônia figura em segundo lugar, depois do Pará, com sete artigos. A abordagem é similar à de Paragominas. A extração seletiva de madeira e o desmatamento progressivo são os dois aspectos enfatizados. Tudo começou com os incentivos governamentais a partir de 1960, fruto de programas de desenvolvimento como Polamazônia e Polonoroeste, resultando em ocupação humana desordenada e interferência agressiva no meio ambiente, processo que culminou com a criação do Instituto Nacional de Colonização e Reforma Agrária (INCRA), em 1970. Tal órgão é apontado como o responável por grande parte da colonização inconseqüente de Rondônia, um "trabalho avassalador, brutal e irracional": Afinal, foi-lhe atribuída, pela ditadura militar, a tarefa de promover o assentamento, naquele Estado, 
de milhares de famílias, em determinado período. "Os custos sociais e ecológicos da empreitada não deveriam ser considerados: o que contava era, tão-somente, cumprir as metas... " ("Para não repetir Rondônia", mar. 1988).

Atraídos pelo seu potencial econômico terras férteis, disponíveis à agricultura, à agropecuária e à extração de madeira, além da caça e da já tradicional extração de borracha, de castanha e das jazidas de minério - a região tornouse um foco de exploração de recursos naturais. Concentradas sobretudo na bacia do Jamari, as atividades de extração de minérios, principalmente de cassiterita, envolvem grandes mobilizações de terra e rocha. Com isso, alteram a hidrodinâmica dos rios, causam assoreamentos e perturbam o ciclo de vida dos peixes migradores. "Toda cadeia trófica, enfim, sofre alterações, com conseqüências imprevisíveis. Além disso, o acúmulo de sedimentos em determinadas áreas criaria ambientes de poças e águas paradas, nos insetos responsáveis pela transmissão da malária"("Rondônia: artérias poluídas", ago.1988).

A partir de 1984, com uma nova onda de migração, conseqüência da pavimentação da rodovia Marechal Rondon (BR 364), que liga a capital, Porto Velho, a Cuiabá, acelerou-se o desmatamento e a extração madeireira. Atualmente, embora os próprios pesquisadores reconheçam que os dados estatísticos sejam discrepantes, aproximadamente $15 \%$ do Estado já está desflorestado.

\section{Acre e Maranhão}

O desmatamento e o extrativismo seletivo da madeira continuam a ser o objeto da atenção dos pesquisadores (principalmente biólogos e botânicos) que estudam outras zonas fitogeográficas da Amazonia. Temos, assim, um texto sobre o estado do Acre e dois sobre o Maranhão. No primeiro caso, os cientistas concentram-se no exemplo positivo de combate ao uso irracional dos recursos florestais: o estabelecimento de seis reservas extrativistas no Acre, em 1988. No segundo caso, além de apresentar um panorama da devastação maranhense, há um texto que enfoca outra iniciativa positiva, a criação da Reserva Biológica do Gurupi, a leste do Tocantins, após expedições feitas por estudiosos do Museu Paraense Emílio Goeldi. O outro artigo descreve a formação do fenômeno hidrodinâmico da pororoca no sistema estuarino baía de São Marcos-rio Mearim-Ponta da Madeira, a $40 \mathrm{~km}$ do oceano e a $2 \mathrm{~km}$ a jusante do porto de Itaqui.

\section{A natureza e os índios na Amazônia}

A vida dos índios na Amazônia, em uma perspectiva etno-ecológica, constitui objeto de vários artigos de antropólogos do Museu Paraense Emilio Goeldi, do Museu Nacional e do Museu do Índio. Dos 66 textos incluídos na categoria Amazônia, 13 tratam da questão indigenismo e meio ambiente. As eco-epidemias, o comportamento em relação à natureza, os mitos, as crenças e símbolos, o drama dos Yanomami nas áreas de garimpagem e a situação dos kayapó são os principais temas abordados.

As alterações ecológicas são apontadas por um epidemiologista como uma das causas do apareamento de freqüentes epidemias, provocando a morte de muitos deles, uma vez que os efeitos de uma doença infecciosa são mais graves em populações nunca expostas a ela. O comportamento em relação à natureza é analisado sob a perspectiva da busca do equilíbrio ecológico, apontando como os índios retiram seu sustento do solo sem danificá-lo: "ao plantar, os Kayapó parecem imitar a natureza. Quando iniciam uma roça, introduzem grande número de espécies e variedades"; o que favorece o equilíbrio da área explorada ("Reflo-restamento indígena" - Especial Amazônia, 1991). Mesmo quando se utilizam de queimadas, o fazem sabiamente, pois para eles, "o fogo tem funções definidas: controla a população de cobras e escorpiões e evita o crescimento excessivo de gramíneas e cipós":

O universo simbólico é abordado em vários artigos que descrevem as práticas "medicinais", a "cura xamanística", as noções de doença. A literatura oral indígena, suas lendas e mitos, e o calendário econômico de algumas tribos também fazem parte desse universo cultural analisado pelos antropólogos.

A situação dramática dos Yanomami nas áreas de garimpo serviu de mote para o exame da 
invasão de áreas indígenas por garimpeiros. A intervenção governamental, no caso, representada pela ação das Forças Armadas é o principal alvo das críticas dos antropólogos. Se antes, nos tempos do Marechal Rondon, os nativos eram vistos como "as muralhas do sertão, indispensáveis para a manutenção e expansão da fronteira", hoje, são vistos como uma "ameaça à soberania nacional". E mais: "Os Yanomami foram (...) citados nominalmente no Projeto Calha Norte dentro dessa perspectiva" ("O Drama dos Yanomami", Especial Amazônia, 1991). A poluição da bacia do rio Alalaú é apontada como outro problema, responsável pela drenagem fluvial de $55 \%$ do território habitado pela tribo dos WaimiriAtroari, devido à extração de cassiterita, comprometendo a própria vida das comunidades locais, uma vez que é do rio que retiram seu sustento e o substrato para a reprodução de sua cultura.

\section{Amazônia - ecossistemas aquáticos}

A água aparece em terceiro lugar (depois das subcategorias recursos florestais e fauna/ índios), no contexto da categoria AMAZÔNIA, com oito artigos. Dois deles abordam o problema da contaminação dos rios por mercúrio, o que vem se alastrando devido à disseminação das atividades de garimpagem na região. Esse tipo de contaminação elimina não só muitas espécies de peixes, mas também quase toda a microfauna aquática, essencial para o equilíbrio ecossistêmico, além de comprometer a saúde humana e animal. Cerca de $55 \%$ do metal utilizado entra diretamente na atmosfera, sob a forma de vapor, o qual, ao ser oxidado, retorna ao solo pela chuva, contaminando rios, florestas e, conseqüentemente, animais terrestres e aquáticos, além de pessoas.

Há ainda estudos sobre a ecologia dos igapós e igarapés, que contribuem para a formação das bacias dos maiores rios da região, isto é, o Solimões, o Negro e o próprio Amazonas. Ao estudar 15 igarapés de águas claras e 20 de águas escuras, um ecólogo esmiúça as características físicas e químicas de cada um e sua contribuição para manter a biodiversidade no complexo ambiental amazônico. O Rio Negro, em particular, é alvo de duas pesquisas que tentam desvendar os mistérios de suas águas escuras, efeito de um pigmento denominado violaceína, que possui ação antibiótica, eliminando a microfauna aquática, o que dificulta a pesca e compromete a sobrevivência das populações ribeirinhas, razões que justificam o título internacional de hungry river (rio da fome).

O impacto ambiental provocado pela construção de hidrelétricas também desperta o interesse de Ciência Hoje. No caso específico da hidrelétrica de Balbina, construída no centro da Amazônia, dois artigos avaliam esse projeto, considerado questionável do ponto de vista técnico e econômico, e desastroso quanto ao aspecto ecológico. Os erros técnicos são apontados minuciosamente, tais como a diferença entre a capacidade nominal de produção da hidrelétrica e a quantidade real de energia que vai gerar. $\mathrm{O}$ projeto prevê cinco turbinas, mas a vazão média anual do rio, no local da barragem é suficiente para garantir o funcionamento de apenas duas. Além disso, a decomposição da floresta inundada forma ácidos que corroem os equipamentos da usina e provocam a morte dos peixes, no reservatório e ao longo trecho do rio, abaixo da barragem.

Do ponto de vista econômico, vários dados também são apresentados, confirmando os pontos discutíveis do projeto. O custo inicial de 383 milhões de dólares quase dobrou, atingindo a cifra de 750 milhões. Finalmente, do ponto de vista ambiental, destaca-se o desaparecimento de grandes áreas de floresta, que contribui para alterar o equilíbrio da fauna local e causar graves danos à saúde das populações ribeirinhas. A água tornou-se inapropriada para consumo humano, causando diarréia, febre, coceiras e feridas na pele; e desapareceram o pescado e os animais de caça.

\section{O MEIO AMBIENTE ALÉM DA AMAZÔNIA EM CIÊNCIA HOJE}

Analisamos, a partir de agora, os textos de Ciência Hoje que tratam da questão ambiental, fora do contex to amazônico. Alguns estão emoldurados pela mesma orientação ecológica geral, mas também nos deparamos com outras categorias temáticas:

\section{POLUIÇÃO}

Este tópico aparece em segundo lugar, com 27 dos 166 artigos de Ciência Hoje. Predominam os 
estudos sobre poluição industrial, destacando-se o caso de Cubatão, com 11 textos. Trata-se de uma ampla abordagem, incluindo histórico da "primeira grande batalha ecológica nacional", efeitos gerais da poluição na saúde da população, bem como efeitos específicos: malformações congênitas, hidrocefalia, hipotiroidismo, deficiência mental, intoxicação sangüínea e mortalidade infantil. Enfocam-se ainda assuntos como "formas defeituosas de organização humana do espaço", condições climáticas versus concentração de indústrias na bacia do rio Cubatão, excesso de elementos poluentes nas águas da região e na atmosfera e levantamento da poluição química, seus efeitos e sua relação com os fatores determinantes de anomalias nos seres humanos, além de evasão e morte de espécies da avifauna regional.

O número inaugural de Ciência Hoje (agosto de 1982) dedica boa parte de sua edição aos problemas desencadeados pela poluição industrial em Cubatão, com sete textos de cientistas de diferentes áreas: Genética, Embriologia, Epidemiologia, Biologia, Demografia, Geografia e Botânica. Ricos em dados estatísticos, os quais relatam que, das indústrias que constituem a base do complexo agroindustrial paulista, saem, diariamente, um milhão de quilos de poluentes por dia, além de 20 mil toneladas de resíduos sólidos deixados nos lixões a céu aberto.

Dos 27 textos, quatro enfocam as novas técnicas de mensuração e controle de poluentes industriais e a análise de seus efeitos no ar, na água e no solo.

A chuva ácida - causada pela acumulação de gases, cinzas e efluentes líquidos decorrentes da combustão de metais tóxicos - é um dos efeitos desse tipo de poluição que mais despertou interesse dos pesquisadores, com três artigos. Um deles examina o fenômeno em termos globais, apresentando dados relativos a países como Inglaterra, Noruega, Alemanha e Brasil. O outro concentra-se no caso Candiota, no estado do Rio Grande do Sul. A região de Cubatão, no estado de São Paulo, e de Criciúma, em Santa Catarina, também são mencionadas como áreas críticas no Brasil, onde há registros de elevados índices de acidez das águas, cujas causas são combustão de metais nas indústrias petroquímicas e metalúrgicas e a combustão de carvão com alto teor de enxofre. O outro texto relaciona o fenômeno da chuva ácida com a queima de florestas, destacando a América do Sul como foco de tal problema.

A questão do efeito estufa é mencionada em dois artigos e duas notas - uma bibliográfica e uma informativa - todos sob o enfoque do "aquecimento global". Um dos artigos reporta-se ao histórico da concentração de gases-estufa na atmosfera desde a Revolução Industrial, destacando seus impactos sobre o aquecimento do planeta, fator resultante dos obstáculos à dissipação da radiação. Outros textos apresentam conotação mais didática. Explicam o que é o efeito estufa, como e porque ocorre e quais seus efeitos físicos e biológicos.

A questão do lixo atômico também faz parte da agenda científica de Ciência Hoje. A principal indagação dos pesquisadores é o que fazer com esse tipo especial de lixo, uma vez que seus resíduos são portadores de alto teor de radioatividade. Tal característica exige seu isolamento da biosfera, "por prazos cuja duração ainda não está fixada $e$ é objeto de intensa discussão nos dias de hoje. De gualquer modo, são prazos extensos, podem atingir dez mil anos, ou até mais" ("Lixo Atômico: o que fazer?", maio 1984). Outro artigo discorre sobre a radioatividade atmosférica natural, em suspensão no ar, nas águas e no solo.

A ênfase da revista em apreço à poluição industrial no município de Cubatão, na Baixada Santista, merece algumas considerações. A primeira delas diz respeito ao engajamento da comunidade científica brasileira, sob os auspícios da SBPC, na denúncia e na elaboração de diagnósticos sobre a poluição ambiental no País. Outro dado é que em 1982, ano em que a revista começou a ser publicada, fez dez anos de realização da Conferência de Estocolmo. A SBPC incluiu uma avaliação da Conferência em sua Reunião Anual, além de ter promovido um seminário, enfocando especificamente a situação de Cubatão. Outro fator a ser considerado diz respeito à expressiva participação de associações comunitárias, sindicatos e outras entidades associativas, as quais juntaram-se às manifestações de ativistas ecológicos e da comunidade científica na denúncia dos índices alarmantes de poluição na Baixada Santista. Percebe-se, assim, a conotação política atribuída ao assunto pela SBPC. 
AGRICULTURA E MEIO AMBIENTE

O terceiro item no elenco temático de Ciência Hoje (com 15 textos) prioriza os processos biológicos de controle de pragas na agricultura, como alternativa isenta de poluição química e seus conseqüentes riscos à saúde humana, da fauna, flora e rios. Grande parte dos estudos enfatiza as conseqüências do modelo agrícola baseado na monocultura, resultado do chamado desenvolvimento agroindustrial, o qual acarretou e acarreta danos contínuos aos agroecossistemas, frutos da quebra do equilíbrio biológico, uma vez que

"... havendo grande densidade de uma ou de poucas espécies de plantas, é maior a disponibilidade de alimento para apenas alguns insetos, ftcando prejudicada a sobrevivência de outros, inclusive parasitóides (insetos que parasitam outros) $e$ predadores. Nisto reside a principal origem das pragas florestais e agrícolas" (Insetos $X$ insetos: nova alternativa para o controle de pragas", maio/jun.1983).

Assim, um determinado tipo de inseto, útil ao equilíbrio ecológico, torna-se nocivo, comoé o caso das espécies fitófagas, que se alimentam de plantas. Ao serem levadas, sem seus respectivos inimigos naturais, para uma região ou país onde antes não havia populações de sua espécie, é comum que esses seres se tornem pragas perigosas, conforme consta do mesmo texto analisado:

"Desse modo, pode-se dizer que as pragas surgiram com a agricultura e aumentaram com a monocultura, $e$ assim como a agricultura é uma antiga conquista do homem, também são antigas as tentativas que este tem feito para eliminar as pragas ou pelo menos mantê-las sob controle".

Apesar de não ser tão recente, o controle biológico de pragas ainda não é empregado em larga escala na maioria dos países do mundo. Tornou-se mundialmente conhecido ainda no final do século XIX, quando, na Califórnia (EUA), pesquisadores conseguiram controlar o pulgão-branco em áreas de cultivo intensivo. Entretanto, trata-se, ainda, de uma prática arrolada como alternativa no contexto da agricultura mundial.
De modo geral, todos os textos que abordam o assunto salientam as vantagens da utilização de bioinseticidas, entendidos principalmente como reguladores naturais da densidade populacional de insetos por meio de outros insetos considerados patógenos, parasitas ou predadores - relações ecológicas consideradas naturais nos ecossistemas e fundamentais para o estabelecimento do equilíbrio biológico.

Além da ênfase ao assunto mencionado, Ciência Hoje dedicou uma edição (jan./fev.1986) à análise minuciosa dos perigos da utilização de defensivos ou agrotóxicos, salientando que

"registram-se no Brasil, até hoje, produtos banidos de outros países; vendem-se, sem restrições, substâncias proibidas; usam-se, fora dos padrões, venenos perigosos. E pouco se conhece sobre as conseqüências; acidentes e casos de intoxicação são acompanhados de forma assistemática; existem apenas pistas sobre os níveis de contaminação de alimentos; falta um centro de referência que defina padrões analíticos aceitos em todo o País. A legislação federal sobre o assunto data de 1934, e as atividades de pesquisa concentram-se em empresas estrangeiras. É, pois, hora de reavaliar as condições de uso desses produtos, cujo consumo, altamente estimulado por sucessivos governos, saltou, em dez anos, de $27.728,8$ para $80.968,5$ toneladas" ("Defensivos agrícolas ou agrotóxicos?", jan./fev.1986).

Os cinco artigos da citada edição apresentam classificação toxicológica dos produtos utilizados no Brasil; estatísticas hospitalares dos casos de atendimento por intoxicação; índices de contaminação da carne bovina; evolução da venda de agrotóxicos no País; e evolução do número de inseticidas e de espécies resistentes. Enfim, trata-se de um quadro sobre os usos e abusos do consumo de defensivos agrícolas no Brasil, alertando a população para os riscos desses produtos para a saúde e a qualidade de vida do homem, bem como para a poluição tóxica dos mananciais, da fauna e flora. 


\section{FAUNA/FLORA}

Esta categoria figura em quarto lugar, com 14 artigos (Tabela 1). Estudos sobre a riqueza da diversidade animal e vegetal estão em primeiro plano, seguidos de pesquisas acerca de aspectos específicos da flora, e, finalmente, particularidades da fauna. Predominam, portanto, as áreas de Biologia e Botânica.

O principal artigo relativo à biodiversidade, O País da Megadiversidade (maio/jun.1992), compara o Brasil com vários países do mundo. Concluem os pesquisadores que, ao contrário do que se pensa, não é nas minas de ferro e alumínio nem na indústria de aço que se concentra a riqueza do Brasil. Seu maior patrimônio está "em seus variadíssimos ecossistemas, que, por reunir o mais elevado número de espécies de organismos do planeta, fazem do Brasil um campeão em matéria de biodiversidade".

Os aspectos específicos da flora estão em seis artigos, que estudam a vegetação costeira no extremo sul do País; a flora de manguesais, restingas e pradarias da América Latina; o potencial de uma planta ornamental no controle da esquistossomose, a "coroa-de-cristo"; a palmeira babaçu; a flora do Pantanal e os distúrbios ambientais. Este último analisa as perturbações, em um ecossistema, causadas pela invasão de plantas exóticas, o que constitui ameaça às espécies nativas, podendo levá-las à extinção.

A fauna silvestre constitui o alvo do interesse da comunidade científica, no que se refere à diversidade animal. As aves do cerrado e os mímicos são mencionados nos dois artigos sobre a questão. O cerrado é caracterizado como umhabitat sazonal, que abriga aves que estão de passagem na época da migração, as quais aproveitam para se reproduzir e depois prosseguem para a Amazônia e outras regiões. O mimetismo entre animais silvestres é estudado como fenômeno ecológico de grande relevância porque está diretamente relacionado com às estratégias de sobrevivência e de comunicação intra e inter-espécies.

\section{ECOSSISTEMAS AQUÁTICOS}

Esta categoria figura em quinto lugar, com nove artigos. Contemplam-se os ecossistemas fluviais e marítimos, abrangendo áreas como lagoas costeiras dos estados do Rio de Janeiro e São Paulo, além do Pantanal Mato-Grossense, litoral do Rio Grande do Sul, particularidades das algas carrageanas e o fenômeno da variação relativa do nível do mar. A derrubada da mata de restinga é apontada como uma das maiores ameaças ao equilíbrio ecológico das lagoas costeiras no estado do Rio de Janeiro. A devastação ocorre em função da obtenção de lenha e de áreas livres para o lançamento de vinhoto. Além do diagnóstico da situação, os cientistas apresentam um elenco de sugestões que, ao serem implementadas, podem garantir a preservação das áreas em referência.

O Pantanal e o litoral gaúcho são mencionados em diversos textos sobre macrófitos aquáticos, aguapés e lagoas costeiras, considerados centros de diversidade biológica. O conteúdo dos textos é altamente técnico, consistindo, por exemplo, na descrição dos macrófitos específicos de cada um dos ecossistemas mencionados. As algas carrageanas são estudadas mais do ponto de vista do seu potencial econômico, como matéria-prima para a fabricação de sorvetes, tintas, ceras e creme dental. Além disso, abordam-se os critérios biológicos de identificação das algas, as diversas famílias, a reprodução e a composição físicoquímica básica das espécies citadas, consideradas polivalentes, devido às possibilidades múltiplas de aproveitamento industrial.

A variação relativa do nível do mar é estudada a partir das previsões de que, no decorrer do próximo século, o nível dos oceanos terá uma elevação global de cerca de $60 \mathrm{~cm}$. Porém, alertam os pesquisadores, uma previsão global não tem sustentação científica, uma vez que se trata de um fenômeno complexo, que depende de muitos fatores, sendo necessário considerar os aspectos regionais, os quais exercerão mais influência no processo. Dados citados pelos pesquisadores confirmam esta premissa, apontando diferentes taxas de afundamento do litoral de deltas e estuários em várias partes do mundo, conforme as características de cada local. Daí porque a conclusão científica refuta o aumento relativo do nível do mar como um "fenômeno óbvio", sendo necessário monitoramento regional para busca de soluções singularizadas. 


\section{ESPÉCIES EM EXTINÇÃO}

A preocupação da comunidade científica com as espécies ameaçadas de extinção figura em sexto lugar no ranking dos temas cobertos pela revista Ciência Hoje. As espécies da fauna silvestre constituem o foco do interesse dos pesquisadores, com seis dos nove artigos, destacando-se mico-leão-dourado, ouriço-preto, baleias, macacos mono-carvoeiros ou muriquis, tartarugas marinhas, sagüis, mico-leão vermelho, macaco-da-noite e outros primatas.

O enfoque dos estudos é essencialmente descritivo e didático, com a preocupação básica de fornecer o máximo de informações ao leitor sobre as espécies ameaçadas. Destacam-se ainda as iniciativas de instituições para preservar tais animais, bem como o trabalho de pesquisadores com o objetivo de reintroduzir tais seres em seu habitat original ou sua reprodução em reservas biológicas. É oportuno ressaltar ainda a conotação de denúncia no discurso dos cientistas, salientando o descaso das instituições responsáveis pela preservação do patrimônio natural do País, bem como a caça predatória ou a matança indiscriminada em quase todas as regiões do Brasil.

Estudos sobre espécies ameaçadas da flora e da avifauna aparecem em segundo plano, com apenas um texto, respectivamente. No primeiro caso, o alvo são as bromeláceas; no segundo, a ararinha-azul. Apesar da riqueza de espécies, como o abacaxi e as ornamentais, alguns tipos encontramse ameaçados pela relação agressiva do homem com a natureza. Tais plantas sofrem face à ação indireta do homem, pois com o desflorestamento e a devastação, as bromeláceas tendem a desaparecer, junto com as árvores derrubadas ou as queimadas. O mesmo ocorre com a ararinhaazul, por ser um tipo de ave muito ligado às palmeiras. Assim, com a destruição dos palmeirais, como por exemplo, para a fabricação de celulose, os ninhos são destruídos e as aves sobreviventes tendem a fugir. A reprodução em cativeiro ou reservas biológicas é apontada como uma das alternativas para a preservação das ararinhas.

A contribuição da Paleontologia para o estudo da preservação de espécies ameaçadas de desaparecimento provocado é outro tema que constitui objeto de análise de Ciência Hoje. Afinal, "a origem e a extinção das espécies costumam ser vistas como duas faces de um mesmo problema: as relações que elas mantêm entre si e com o ambiente selecionarão aquelas que sobreviverão no período seguinte $e$ as que se extinguirão. Há muito os paleontólogos perceberam que, em determinadas épocas do passado, ocorreu maior número de extinções que em outras, considerando-as como 'crises' na história da vida" (Padrões de Extinção no registro Fóssil, jul.1989).

\section{ECO-HISTÓRIA}

A categoria Eco-História registrou seis artigos - cada um sobre temas distintos - na perspectiva de uma história dos desastres ambientais, cujo objetivo é "rastrear o passado em busca das mudanças climáticas, das alterações no curso dos rios, no regime dos ventos, na estrutura do solo" ("Desastres Ambientais na Capitania de Goiás", jan./fev.1991). No caso desse artigo, a análise remete a 1773, para descrever o processo predatório de extração mineral, que causou o assoreamento dos ribeirões e a impossibilidade de cultivo agrícola em algumas regiões, onde o solo tornou-se "desnudado e abrasado". Outro texto, Uma História da Caça à Baleia (maio/jun. 1992), historia esse tipo de pesca, a partir de 1602, no litoral sul do estado da Bahia, introduzida no Brasil depois que Felipe III, rei de Espanha e Portugal, concedeu alvará a um grupo de marinheiros, permitindo o privilégio de caçar baleias nas costas brasileiras. Com riqueza de dados estatísticos, históricos e ainda com fotos e ilustrações, o texto apresenta de forma minuciosa a evolução dessa atividade, a qual constitui, hoje, a causa principal da ameaça de extinção a várias espécies desse mamífero marinho.

$\mathrm{O}$ artigo "Itaparica: novos destinos" (ago.1989), apesar de remeter a um período histórico recente - a década de 1970 -, faz referência a uma época bem anterior, como se vê desde a introdução:

"Itaparica desafiou a história quando as águas do São Francisco inundaram vestígios de dez mil anos atrás. $O$ rio levou a maioria das 'itacoatiaras', 
inscrições de homens pré-históricos feitas nas suas margens. Um imenso tesouro arqueológico permanece submerso com os sonhos de milhares de gerações que o presente teima em ignorar".

Ainda relacionado com o rio São Francisco, o texto " O Arapaçu-do-São-Francisco 60 anos depois" (jul.1988) trata de descoberta de uma espécie da avifauna brasileira ainda não identificada pela ciência. Tal descoberta ocorreu em 1926, pela ornitóloga alemã Emilie Snethlage, no Brejo Jamaria, no estado de Minas Gerais, à margem esquerda do rio.

Entre os outros temas abordados, destacam-se as empreitadas de naturalistas e botânicos italianos no Brasil, no período de 1800 a 1850 e suas contribuições para a classificação das plantas típicas da flora nativa e um estudo sobre a originalidade da terra na região de Os Sertões.

\section{DEVASTAÇÃO/DESMATAMENTO}

A inundação de áreas florestais e habitacionais é o carro-chefe dos estudos sobre devastação publicados por Ciência Hoje (três dos seis textos). Destacam-se as inundações provocadas pela construção de represas e barragens, como a represa de Itaparica no rio São Francisco e represas da Barra Bonita e do Lobo, ambas no estado de São Paulo.

A barragem de Itaparica foi objeto de dois artigos minuciosos, abrangendo não só os impactos ambientais, mas outros fatores, como a interferência nas relações sociais dos sertanejos e as alterações na economia local e nas relações de trabalho:

- "nas bordas do grande lago da represa de Itaparica a vida mudou. Os sertanejos que viram suas terras desaparecerem sob as águas agora compreendem a urgência de se ter uma organização sindical atuante. $O$ grande lago sacudiu velhos hábitos e conscientizou o pequeno agricultor. Ele aprendeu depois da invasão da velha caatinga a lutar pelos seus direitos";

- "as repercussões causadas pela construção da Usina Hidrelétrica de Itaparica atingiram, além do meio ambiente, as relações sociais na região sertaneja, alterando tanto a economia local como o modo de vida dos habitantes";

- "... se em algumas áreas a implantação de agroindústrias modifica o quadro local, tornando predominante o trabalho assalariado, em outras - mais distanciadas da influência direta desses complexos empresariais - as antigas relações, como a parceria, o comodato, se incorporam à produção, embora redefinidas pelo patamar de exigências compatível com a acumulação de capital em seu novo estágio" (Terra por terra na beira do grande lago, ago.1989).

Um dos estudos, contudo, concentra-se no diagnóstico da devastação nas áreas adjacentes tá represa, ressaltando que, deliberadamente, "optou-se, porém, por desmatar toda a vegetação do núcleo de colonização de Petrolândia". Com isso,

-"o lago de Itaparica provocou a inundação das cidades de Petrolândia e Itacuruba $(P E)$, de rodelas e do distrito de Barra do Tarrachil (BA). Foram submersas 4.160 moradias, com o que se desalojaram 36 mil habitantes, dos quais $55 \%$ na zona rural e $45 \%$ nas áreas urbanas".

- a inundação do reservatório trouxe inevitáveis prejuízos à fauna terrestre, típica de clima semi-árido("Bichos e plantas no doce mar do sertão", ago.1989);

O estudo sobre a construção de represas artificiais no estado de São Paulo, apesar de analisar dois casos determinados, a Represa de Barra Bonita e a Represa do Lobo, traz dados sobre o impacto geral do crescimento de tal empreitada, resultando na inundação de $15 \mathrm{mil} \mathrm{km}$ de terra firme, nos últimos anos. Ressalta que:

- "o manejo correto de várias represas de uso múltiplo e localizadas ao longo de um mesmo rio é um verdadeiro desafio, pois precisa levar em conta as caracteristicas dos ecossistemas envolvidos";

- “a rápida inundação dos reservatórios e as grandes dimensões assumidas por esses ecossistemas artificiais têm produzido inúmeras alterações nos sistemas 
hidrológico, atmosférico, biológico e social nas regiões em que são construidos e nas áreas atingidas pelos lagos artificiais" (Ambiente, represas e barragens, nov./ dez.1986).

O fenômeno das enchentes no Sul do País completa o quadro de Ciência Hoje sobre a devastação causada pelas inundações, do pronto de vista das Geociências. Além dos aspectos geológicos, destacam-se os impactos das enchentes sobre áreas habitadas, principalmente os sítios urbanos, destacando casos específicos como Blumenau e Joinville ("Enchentes em Santa Catarina: o fenômeno vira rotina", jun.1988).

A devastação de sítios arqueológicos e seu patrimônio de inscrições rupestres é noticiada na seção "É Bom Saber", citando o caso da destruição do Arco do Calcário, em Minas Gerais, por uma empresa extratora de cal, que dinamitou o local. Este texto foge totalmente ao padrão editorial dos demais, pois apresenta caráter jornalístico, típico da seção da revista.

\section{PARQUES/ESTAÇÕES/ RESERVAS ECOLÓGICAS}

Cinco grandes Parques Nacionais Brasileiros (PNB's) foram contemplados pelos estudos publicados porCiência e Cultura: Parque Nacional das Emas, Parque Nacional do Itatiaia, Parque Nacional da Serra do Cipó, Parque Nacional do Araguaia e Parque Nacional de Abrolhos. Inclui-se ainda a Reserva Biológica do Gurupi.

Um dos primeiros artigos da série menciona diversos aspectos da definição, caracterização e objetivos legais dos Parques, com base na legislação que os regulamenta. São definidos pelo regulamento dos Parques Nacionais Brasileiros, aprovado pelo Decreto no. 84.071, de 21/09/1979, como "áreas geográficas extensas e delimitadas, dotadas de atributos naturais excepcionais, objeto de preservação permanente, submetidas à condição de inalienabilidade e indisponibilidade no seu todo" (Art. $1^{\circ}$ ) que se destinam a "fins científicos, culturais, educacionais e recreativo"; cabendo às autoridades "preservá-los e mantê-los intocáveis (Art. $2^{\circ}$ ). O mesmo documento enuncia ainda que "o objetivo principal dos parques nacionais reside na preservação dos ecossis-temas naturais englobados contra quaisquer alterações que o desvirtuem" (Art. 1ㅇ), e que o "uso e a destinação das áreas que constituem os parques nacionais devem respeitar a integridade dos ecossistemas naturais abrangidos" (Art. 3\%).

Além dessa preocupação didática, os demais textos, de modo geral, apresentam uma caracterização minuciosa dos PNB's, tanto em seus aspectos positivos como negativos. Predominam os primeiros, com estudos da área de Biologia Marinha, Zoologia e Botânica, nos quais são ressaltados a riqueza e a grandeza de alguns PNB's:

- "a região de Abrolhos, no litoral do sul da Bahia, apresenta uma das áreas de maior riqueza e diversidade de vida marinha no litoral brasileiro"(Um parque nacional para Abrolhos - set./out., 1982);

- "... para os cientistas, existe ali um laboratório natural. Para os turistas, um imenso jardim. Para todos nós, uma região propícia ao desenvolvimento de programas de educação sobre o meio ambiente" ("Campos Rupestres, jul./ago.1986).

A criação da Reserva Biológica do Gurupi, no oeste do Maranhão, também é saudada com otimismo, com ênfase para a riqueza natural do ecossistema contemplado pela citada reserva, a primeira do Estado:

"o Maranhão é particularmente rico em ecossistemas. Ao longo da costa, estendem-se mangues, dunas de areia e restingas. As bacias inferiores de seus principais rios formam cadeias de lagoas com extensos pantanos e campos inundados sazonalmente" ("Uma reserva biológica para o Maranhão", jul.1986).

Entretanto, apesar do encanto dos Parques, ressaltado sobretudo pelos botânicos, os biólogos manifestam-se com indignação acerca da depredação do patrimônio natural dos PNBs:

"... mas a depredação continua: mais da metade da área do Parque Nacional da Serra do Cipó $(M G)$ está em mãos de particulares e 'caçadores de orquídeas' derrubam plantas que, às vezes, têm mais de 500 anos de idade. Até quando?" ("Campos rupestres", jul./ago.1986). 


\section{POLÍTICA AMBIENTAL}

O item política ambiental aparece basicamente sob a forma de notas e comentários bibliográficos. Há apenas um estudo mais detalhado, que enfoca a situação brasileira em face da questão nuclear. Grande parte do tex to limita-se a repetir os chavões apocalípticos de uma possível catástrofe atômica, assemelhando-se a um ensaio de ficção científica, ao descrever o cenário hipotético do bombardeamento, a partir do Pólo Norte. Entretanto, questiona o alheamento do Brasil em relação ao tema, salientando o fato de que, em caso de qualquer acidente nuclear nos países da América do Norte, a Amazônia brasileira seria drasticamente prejudicada pela radioatividade, afetando a atmosfera, os rios, a vegetação e a fauna. Apesar de todos esses riscos, o Governo brasileiro permanece indiferente a tal problema, na visão dos pesquisadores.

Quanto aos comentários e notas bibliográficas, das três obras enfocadas, duas abordam a política brasileira de meio ambiente no contexto internacional, tendo como parâmetro as recomendações do relatório Nosso Futuro Comum e as críticas do Greenpeace. A outra analisa as posições do Governo, com base nos pronunciamentos em eventos nacionais. Percebe-se, assim, a nítida relação entre o internacional e o nacional, no que se refere à abordagem dos temas concernentes à política ambiental. Também são enfocados outros atores, considerados importantes no cenário da política ambiental brasileira, tais como: industriais e empresários, cientistas, meios de comunicação pública e Organizações Não Governamentais (ONGs). O conteúdo dos textos é mais informativo que analítico. Os cientistas, contudo, mesmo sendo apontados como atores da política ambiental, pelo que se pode inferir da cobertura de Ciência Hoje, mantêm certa distância em relação ao tema. A amostra examinada não registra um só artigo acerca desse tópico. Nem mesmo os cientistas sociais se manifestaram, ao longo dos 30 meses em estudo.

RIO 92

Quanto à Conferência da Organização das Nações Unidas (ONU) sobre Meio Ambiente e Desenvolvimento, a revista Ciência Hoje publicou quatro textos, todos no primeiro semestre de 1992. Deste total, temos apenas um artigo opinativo, assinado por um cientista. Os demais são um editorial, uma entrevista e um artigo. Todos são relevantes e oportunos, mas podem ser considerados mais jornalísticos do que de divulgação científica. Mesmo o artigo de autoria de um cientista, sobre "Mineração, Meio Ambiente e a Rio 92", tem essa característica. Assemelha-se ao formato de uma grande reportagem interpretativa, ou seja, apresenta dados, fatos e tece considerações de cunho opinativo.

O editorial, "Um Futuro Pouco Comum" (maio/jun.1992), comenta o fato de os Estados Unidos e outras potências terem se recusado a assinar a Convenção sobre Biodiversidade, sinal claro do desejo de continuar controlando os instrumentos da biotecnologia para a exploração de recursos naturais. Discorre ainda sobre outros pontos de divergência entre as nações, como a proteção à propriedade intelectual e industrial, manifestações de abuso de poder econômico e as expectativas da comunidade científica e da sociedade brasileira em relação ao evento.

A entrevista, realizada com um representante do Brasil na Organização das Nações Unidas para a Educação, Ciência e Cultura (UNESCO), traça um paralelo entre a concepção da Conferência de Estocolmo, realizada em 1972 e da Rio 92, destacando, no primeiro caso, a importância da tomada de consciência e no segundo, o amadurecimento dessa consciência social. Já o deputado Fábio Feldman, presidente da Comissão de Meio Ambiente da Câmara dos Deputados e sócio da SBPC, que assina o artigo, destaca a atuação das $\mathrm{ONG}^{\prime}$ 's no processo preparatório da Conferência e da relação da problemática ambiental com outros temas sociais igualmente importantes. Afinal, "não existirá solução para a degradação do meio ambiente sem justiça social $e$ redistribuição de renda em nível mundial"; afirma o deputado, em seu artigo.

\section{CONSIDERAÇÕES FINAIS}

Antes dos comentários finais propriamente ditos, retomaremos a hipótese central que norteou essa pesquisa, ou seja, a de que a divulgação científica contribuiu para que o tema adquirisse 
mais repercussão pública, passando a despertar mais interesse social, fazendo com que a Ecologia deixasse de ser assunto de especialistas, à medida que outros ramos do saber passaram a se dedicar ao estudo do fenômeno, sobretudo com as contribuições oriundas do campo das Ciências Sociais, como foi o caso da Antropologia, inicialmente, e, depois da Ciência Política Sociologia e Economia. Esse foi, a nosso ver, um dos fatores importantes para a passagem da ciência ecológica, produzida por especialistas, para a consciência ecológica, quando se passou a debater publicamente o assunto, uma vez que o laboratório dos cientistas sociais é a discussão acadêmica, em primeira instância, e o debate público, o qual retroalimenta a discussão e fornece elementos para que as idéias sejam repensadas, aprimoradas e novas questões sejam incorporadas. O segundo, decorrente do primeiro, baseia-se na idéia de que esse feedback oferecido pela sociedade também é importante para a produção de conhecimentos sobre meio ambiente, uma tentativa natural da comunidade científica de atender às demandas emergentes da sociedade. Com isso, não só as Ciências Sociais, mas todas as áreas científicas passaram a realizar estudos que tentassem responder a essas demandas, direta ou indiretamente.

Entretanto, o que podemos inferir, depois da análise apresentada, é que nossos pressupostos iniciais não se confirmam totalmente. A divulgação científica realizada pela SBPC também apresenta suas vicissitudes, como a hegemonia das Ciências Naturais; a pouca expressividade das Ciências Sociais; o caráter diagnosticador; o tom denuncista, em alguns momentos; e a fragilidade na politização do assunto.

É necessário, portanto, relativizar a importância da divulgação científica sobre meio ambiente, tendo em vista os dados acima apresentados e discutidos.

Entre as características gerais do conteúdo da revista Ciência Hoje destacam-se:

1 - Concentração nos estudos de avaliação de impactos e efeitos da degradação ambiental - é o que observamos na grande maioria dos estudos, de diversas áreas. Categorias como poluição, devastação, fauna/flora, espécies ameaçadas de extinção, desertificação e ecohistória exemplificam tal tendência.

2 - Atenção às tendências da divulgação científica internacional - é o que observamos principalmente no que se refere aos "temas globais", como efeito estufa, mudanças climáticas etc. $\mathrm{O}$ interesse é de acompanhar o que a comunidade científica internacional está produzindo sobre tais assuntos.

3 - Ampla agenda temática - em relação à Ciência e Cultura, apresenta um enfoque mais amplo, abordando temas ecológicos sob a perspectiva de diferentes áreas científicas, inclusive as sociais, como Antropologia;

4 - Didatismo - até por ser dirigida ao "público leigo", inclusive a estudantes do ensino médio, procura apresentar os textos de forma didática, dividindo-os em partes, além da utilização de quadros, gráficos e outras ilustrações; com o intuito de facilitar a compreensão da leitura.

5 - Preocupação com o conteúdo informativo - devido a seu caráter de periódico de divulgação científica, Ciência Hoje não prioriza tanto os cânones científicos no estudo de temas ecológicos, mas a informação em si, o que a faz se aproximar do enfoque jornalístico.

Após a análise, podemos afirmar que Ciência Hoje não possui uma agenda própria, ou seja, seu conteúdo é pautado por outro periódico da SBPC: Ciência e Cultura ${ }^{3}$. Na realidade, são dois periódicos distintos, com objetivos diferentes, mas que o segundo constitui uma extensão do primeiro. As diferenças estão mais na forma com que os temas são abordados do que no conteúdo em si. Grosso modo, poderámos afirmar que Ciência Hoje é uma espécie de "tradução" de Ciência e Cultura para o público leigo. Entretanto, apesar dessa característica geral comum, não podemos ignorar as particularidades de cada um dos periódicos em exame. Para tanto, consideramos que a melhor alternativa é a comparação entre algumas das categorias comuns às duas revistas, a começar pela categoria Amazônia, a principal em ambas as revistas.

Aliás, a revista Ciência Hoje é que revela maior sintonia com as questões ecológicas globais,

\footnotetext{
(3) A pesquisa original que deu origem a este artigo também analisou os textos publicados por Ciência $e$ Cultura.
} 
com destaque para os seguintes temas: aquecimento global, mudanças climáticas, destruição da camada de ozônio, biodiversidade e desflorestamento. O que podemos inferir é que a globalização do debate ecológico, no que concerne aos estudos da comunidade científica brasileira sobre a Amazônia, constitui mais uma tentativa de atender a eventuais demandas externas do que a um interesse próprio do campo científico em si. O que nos leva a essa conclusão é o fato de que quanto maior o interesse de divulgação científica do periódico, maior a relação com as questões globais. Ciência e Cultura, que não tem o objetivo de divulgação científica, é o periódico que menos se volta para a agenda ecológica planetária. Já a revista Ciência Hoje, dirigida a um público mais amplo, apresenta vinculação maior com a agenda global.

EmCiência Hoje, percebemos que o espectro da divulgação científica sobre ecologia é abrangente. Entretanto, igualmente, predomina o olhar das Ciências da Natureza. As Ciências Sociais aparecem quase exclusivamente sob o enquadramento da Antropologia, que se interessa basicamente pela questão indígena. Mesmo se tratando de um veículo considerado de difusão científica, voltado para o grande público, há quase uma reedição da orientação editorial geral de Ciência e Cultura. Autores como Edgar Morin $(1973,1991,1992)$ apontam para uma significativa contribuição das Ciências Sociais na passagem de uma ciência ecológica (produzida por e para especialistas) para uma consciência ecológica, que implica no envolvimento de vários segmentos sociais no debate sobre o assunto. Contudo, isso ainda não se reflete na forma como a SBPC realiza sua divulgação científica, pelo menos em seus instrumentos institucionais de divulgação científica, como a revista Ciência Hoje.

\section{REFERÊNCIAS BIBLIOGRÁFICAS}

BARDIN, Laurence. Análise de conteúdo. Lisboa: Presença, 1977.

FERNANDES, Ana Maria. A construção da ciência no Brasil e a SBPC. Brasília: EdUnB, 1990.

FERREIRA, Lúcia Costa. Os fantasmas do vale: qualidade ambiental e cidadania. Campinas: EdUnicamp, 1993.

LEIS, Héctor Ricardo. O labirinto: ensaios sobre ambientalismo e globalização. São Paulo: Gaia,1996.

MACHADO, Roberto. Ciência e saber a trajetória de Foucault. Rio de Janeiro: Graal,1981.

MACULAN, A. M. A política brasileira de ciência e tecnologia. Novos Estudos CEBRAP, São Paulo, n. 43 , nov. 1995.

MORIN, Edgar. Le paradigme perdu: la nature humaine. Paris:Éditions du Seuil.1973.

La méthode: les idées. Paris: Éditions du Seuil.1991a.v. 4.

La pensée écologisée. In: MORIN, Edgar et al. Un nouveau commencement. Paris: Éditions du Seuil,1991b. p.179-193.

. Ciência com consciência. Lisboa: Publicações Europa-América,1992.

STONE, P. A análise de conteúdo da mensagem. In: CONH, G. (Org.). Comunicação e indústria cultural. São Paulo: Poneira, 1987.

VIOLA, Eduardo; LEIS, Héctor R. A evolução das políticas ambientais no Brasil, 1971-1991: do bissetorialismo preservacionista para o multissetorialismo orientado para o desenvolvimento sustentável. In: HOGAN, Daniel J.; VIEIRA, P. Freire (Org.) Dilemas socioambientais e desenvolvimento sustentável. Campinas: EdUnicamp,1992. p.73-102. 